\title{
Elderly donor liver grafts are not associated with a higher incidence of biliary complications after liver transplantation: results of a national multicenter study
}

\author{
Westerkamp AC, Korkmaz KS, Bottema JT, Ringers J, Polak WG, \\ van den Berg A, van Hoek B, Metselaar HJ, Porte RJ. Elderly \\ donor liver grafts are not associated with a higher incidence of biliary \\ complications after liver transplantation: results of a national \\ multicenter study.
}

Abstract: Background: Liver transplantation with livers grafts from elderly donors has been associated with a higher risk of biliary complications. The aim of this study was to examine whether our national protocol could contribute to a lower incidence of biliary complications.

Methods: All adult recipients in the Netherlands transplanted with a liver from an elderly donor $(\geq 65 \mathrm{yrs} ; \mathrm{n}=68)$ in the period January 2000 July 2011 were matched with recipients of a liver from a donor $<65 \mathrm{yr}$ ( $\mathrm{n}=136$ ). Outcome parameters were $90-\mathrm{d}$, one-yr, and three-yr patient/ graft survival rates, biliary complications (non-anastomotic stricture, anastomotic stricture, biliary leakage, and post-transplant cholangitis), and postoperative hepatic ischemic injury serum markers (AST/ALT). Results: The median cold ischemia time (CIT) was 7:25 (h:min) in the group recipients of an elderly donor liver graft. Ninety-day, one-yr, and three-yr patient/graft survival rates were similar between the group with an elderly donor liver and their younger controls. Moreover, no differences were found in the incidence of biliary complications and postoperative levels of AST/ALT between the two groups. Conclusion: Transplantation of livers from elderly donors ( $\geq 65 \mathrm{yr})$ is not associated with a higher incidence of biliary complications, in a national policy wherein the CIT is kept short.

\author{
Andrie C. Westerkamp ${ }^{a}$, \\ Kerem S. Korkmaz ${ }^{\mathbf{b}}$, \\ Jan T. Bottema ${ }^{a}$, \\ Jan Ringers ${ }^{c}$, Wojciech G. Polak ${ }^{d}$, \\ Aad van den Berg $^{\mathrm{e}}$, \\ Bart van Hoek ${ }^{\text {, }}$ \\ Herold J. Metselaar ${ }^{\dagger}$ and \\ Robert J. Porte ${ }^{\mathrm{a}}$ \\ aSection of Hepatobiliary Surgery and Liver \\ Transplantation, Department of Surgery, \\ University of Groningen, University Medical \\ Center Groningen, Groningen, ${ }^{b}$ Department of \\ Gastroenterology and Hepatology, \\ 'Department of Surgery, Leiden University \\ Medical Center, Leiden, 'Department of \\ Surgery, Erasmus Medical Center, Rotterdam, \\ eDepartment of Gastroenterology and \\ Hepatology, University of Groningen, \\ University Medical Center Groningen, \\ Groningen, and ${ }^{\mathrm{f}}$ Department of \\ Gastroenterology and Hepatology, Erasmus \\ Medical Center, Rotterdam, The Netherlands
}

Key words: biliary complications - elderly donors - liver transplantation - survival

\section{Corresponding author: Robert J. Porte, MD, $\mathrm{PhD}$, Section of Hepatobiliary Surgery and Liver Transplantation, Department of Surgery, University of Groningen, University Medical Center Groningen, PO Box 30.001, 9700 RB Groningen, The Netherlands. \\ Tel.: +31 50 3612896; fax: +3150 3614873; e-mail: r.j.porte@umcg.nl}

Conflict of interest: None.

Accepted for publication 18 May 2015
One of the main challenges in liver transplantation (LT) has become the widening gap between donor organ availability and the number of patients on the waiting list for LT. One way to decrease the shortage of liver donor grafts is the use of extended criteria donor (ECD) livers, which carry a higher risk of graft failure. Advanced donor age is one of the criteria to classify a donor liver as ECD liver (1). Older livers have an impaired regenerative capacity (2-4) and are subsequently more susceptible for ischemia/reperfusion (I/R) injury (5-7). Proposed mechanisms are a decline in liver volume, impaired response to oxidative stress, diminished rates of DNA repair, and a reduced 
expression of growth regulatory genes $(2,7)$. Donor livers with advanced age $(\geq 65 \mathrm{yr})$ are therefore not widely accepted for LT, especially if other risk factors are present such as a (expected) prolonged cold ischemia time (CIT) (7), donation procedure after circulatory death (DCD) (8), graft steatosis ( $>30 \%$ macrovesicular steatosis) (9), and recipients' positive hepatitis $\mathrm{C}$ virus (HCV) status (10).

In the Netherlands, the discrepancy between the number of donor livers and candidates for LT remains a huge problem, resulting in a $15 \%$ mortality rate on the national waiting list in 2013 (11). The three liver transplant centers in the Netherlands, therefore, agreed to consider all potential donors for liver donation regardless donor age. Due to this national policy, the average donor age has increased during the last decade and the percentage of elderly donors ( $\geq 65 \mathrm{yr}$ ) has increased in parallel with this. Allocation of all donor livers is based on a patient-oriented system in which priority is defined by the model for end-stage liver disease (MELD) score.

Biliary complications, including non-anastomotic biliary strictures (NAS), are a major cause of mortality and morbidity after LT (12). A singlecenter report suggested that NAS are more frequent after transplantation of livers from donor with advanced age, especially when the CIT is longer than $10 \mathrm{~h}$ (13). However, it remains unclear whether short CITs could contribute to a lower incidence of NAS when elderly donor livers are used for LT. Moreover, data about the rate of other biliary complications, such as biliary leakage and post-transplant cholangitis after LT with elderly donors, are not fully known.

We, therefore, conducted a Dutch multicenter study to examine outcome after transplantation of liver grafts from elderly donors ( $\geq 65 \mathrm{yr})$. We specifically focused on the incidence of biliary complications as NAS, anastomotic strictures (AS), biliary leakage, and post-transplant cholangitis, within a national policy ensuring short logistics.

\section{Patients and methods}

\section{Study population}

In this retrospective study, all adult recipients undergoing a full-size LT in the period January 2000 till July 2011 were reviewed. All three Dutch transplant centers (Groningen, Leiden, and Rotterdam) participated in this national study. Pediatric transplants (age $<18 \mathrm{yr}$ ), retransplantations, living donations, and combined organ transplantations were excluded. Sixty-eight adult patients with a primary liver graft derived from a 65 -yr or older donor formed the basis of this study. Of all 68 patients, 29 underwent LT in Groningen, 26 in Rotterdam, and 13 patients received a liver graft from an elderly donor in Leiden. All patients had a minimal follow-up period of two yr, and follow-up was complete for all patients until the first of June 2013. Characteristics of the patients, including donor and recipient variables, as well as surgical factors were obtained from a prospectively maintained computer database of the Dutch Transplantation Foundation (NOTR). When necessary, the original patient notes were reviewed for missing information. The percentage of missing variables was $3 \%$. According to national legislation, this type of retrospective analysis using anonymous data is allowed in the Netherlands and does not require informed consent from the individual patients.

To examine the effect of advanced donor age on outcome after $\mathrm{LT}$, all recipients receiving a liver graft $\geq 65$ yr were matched at random in a 1:2 ratio with control recipients, who received a liver from a donor below $65 \mathrm{yr}$ in the same time period. To eliminate any confounding effect of a "center effect" (14), the matching process was stratified per transplant center. Matching was based on the following variables: type of donor graft (donation after brain death [DBD] or DCD), MELD score ( \pm 5 points), and recipient age $( \pm 5 \mathrm{yr})$. The MELD score was calculated on the day of LT disregarding extra points for standard or non-standard exceptions.

National policy for allocation and transplantation of elderly donor livers

Donor liver allocation in the Netherlands is based on a patient-oriented, MELD score-based system. The three transplant centers share one national waiting list and donor livers that come available are first offered to the patient with the highest MELD score (either based on laboratory values or exceptional MELD points). This allocation process is not different for ECD livers; however, centers are allowed to refuse a potential high-risk donor liver (i.e., from an elderly donor) for a specific recipient. Reasons for declining an ECD liver may include a high recipient MELD score, positive $\mathrm{HCV}$ recipient status, or a large age difference between donor and recipient. The refused graft is subsequently offered to the next recipient on the waiting list. According to the Dutch national protocol for DCD donors, donor age above $60 \mathrm{yr}$ is a contraindication for liver donation, which resulted in a very sparse use of elderly DCD livers in this study. In general, 


\section{Westerkamp et al.}

elderly donors are accepted for liver donation when there are no other major risk factors for early graft failure such as moderate or severe steatosis ( $>30 \%$ macrovesicular steatosis), extensive comorbidity in the donor, or a long $(>5 \mathrm{~d})$ intensive care unit (ICU) admission of the donor. Assessment of graft steatosis in our study consisted of a combination of macroscopic inspection of the donor liver by the surgeon during organ procurement and clinical assessment based on the donor's medical history, current condition, and laboratory studies. Frozen section liver biopsy was not standard part of donor evaluation in the Eurotransplant area. Additionally, ultrasonography or computer tomography scanning was not routinely performed prior to donation to evaluate liver steatosis in the donor, as described previously (15).

All three transplant centers had a general policy to try to keep the CIT as short as possible. Generally, the surgical procedure in the recipient was started as soon as quality aspects of the graft were discussed with the surgeon performing the donor procedure. In many cases, the recipient operation had advanced that far, that the donor liver could be immediately implanted upon arrival after the back table procedure. The preferred recipient operation was the cava-sparing piggyback technique, which resulted in a shorter anastomosis time in comparison with the classical implantation technique (one vs. two caval anastomoses).

\section{Donor and recipient characteristics and surgical variables}

The donor risk index (DRI) was calculated according to Feng et al. (16), with minor adjustments for the Eurotransplant population as described by Braat et al. (17) (considering all donors Caucasian and local). In addition, the following donor variables were collected and included in the analyses: gender, body mass index (BMI), causes of death, type of donor (DBD or DCD), and length of stay in the ICU. Recipient variables collected and included were as follows: age, gender, year of transplantation, body mass index (BMI), indication for transplantation, MELD score, recipient status on the Eurotransplant waiting list (elective vs. high urgency), time on the waiting list, length of stay in the ICU, and the need for retransplantation. With respect to the surgical variables, the following parameters were examined: graft implantation technique (conventional vs. piggyback), CIT, warm ischemia time (WIT), type bile duct anastomosis, and amount of total blood loss.

\section{Outcome parameters}

Primary non-function (PNF) was defined as nonlife-sustaining function of the liver requiring retransplantation or leading to death within seven $d$ after LT. Graft and patient survival rates were assessed at 90-d, one-yr, and three-yr after LT. Graft survival was defined as the time period between LT and patient death or retransplantation. Patient survival was defined as the time period between LT and patient death. The period of $90 \mathrm{~d}$ after LT was chosen because the most important impact of CIT on graft function should be evident within this time period $(7,16)$. Bile duct strictures were classified as either at the site of the anastomosis (AS) or non-anastomotic strictures (NAS), as diagnosed by biliary imaging including endoscopic retrograde cholangiopancreatography, magnetic resonance imaging, or percutaneous transhepatic cholangiography. Based upon the first date of presentation, cases of NAS were subdivided into two groups: early NAS defined as presentation within one yr and late NAS with presentation after one yr. Postoperative cholangitis was diagnosed on clinical symptoms (chills, fever) in combination with laboratory values indicating cholangitis. For post-transplant cholangitis, antibiotics were given. Biliary leakage was always confirmed by biliary imaging. If necessary, biliary leakage was resolved by endoscopic treatment or surgical intervention. Occurrence of hepatic artery thrombosis was diagnosed with Doppler ultrasonography (performed routinely on postoperative day 1,4 , and 7 or more often when clinically indicated) and was always confirmed by CT angiography or abdominal exploration. HCV recurrence was determined on the basis of liver histopathology as reported by an experienced local pathologist in combination with clinical, biochemical, and virological findings. Liver graft $I / R$ injury markers were assessed by serum levels of aspartate aminotransferase (AST) and alanine aminotransferase (ALT) on day 1, 3, and 7 after LT.

\section{Statistical analysis}

Categorical variables were presented as numbers and percentages. Groups were compared using the Pearson $\chi^{2}$ test or Fisher's exact test if appropriate. Continuous variables were expressed as medians with (interquartile) ranges (IQR), and groups were compared using the Mann-Whitney $U$-test. Patient and graft survival was analyzed according to the Kaplan-Meier method, and differences between groups were investigated using the log-rank test. Statistical significance was indicated by $p$-values of 
$<0.05$. Statistical analyses were performed using the statistical software package SPSS version 22.0 (SPSS Inc, Chicago, IL, USA).

\section{Results}

Patient characteristics

Recipient, donor, and surgical characteristics of the study group and their matched controls are presented in Table 1. As expected, there were no significant differences for the matching variables between the study group and the control group (transplantation center, type of liver graft, MELD score, and recipient age). The median CIT in the study group with elderly donors was $7 \mathrm{~h}$ and 25 min (IQR 6:23-9:38 h:min). The DRI was significantly higher in recipients of elderly donor liver grafts compared to their controls. However, the clinical importance of these differences in DRI score may be not relevant because elderly donors automatically achieve due to their advanced age more points for the DRI score compared to younger donors. Moreover, the cause of donor death differed among older donors and their controls. Cerebrovascular causes (e.g., cerebral stroke) of death were more frequently seen in the elderly donors. In addition, the donor BMI was significantly higher in the study group with elderly donors in comparison with their younger controls. For all other variables, no statistically significant differences were found between the two groups.

The impact of elderly donor age on patient and graft survival

Ninety-day, one-yr, and three-yr patient and graft survival rates after LT are presented in Table 2. The median postoperative follow-up was 58 months (range, 30-90 months). Patient survival rates were not significantly different between recipients of an elderly donor liver ( $\geq 65 \mathrm{yr}$ ) and recipients of a younger graft $(<65 \mathrm{yr})$. In addition, no significant differences were found in $90-\mathrm{d}$, one-yr, and three-yr graft survival between the two groups.

\section{Postoperative outcome and biliary complications}

Postoperative outcome and complications are summarized in Table 3. The incidence of PNF in the group with elderly donors was not statistically significantly different from that in the control group of younger aged donors (3\% in the study group vs. $4 \%$ in the control group, respectively). Furthermore, there were no significant differences in the number of retransplantations between the two groups $(7 \%$ in the study group vs. $8 \%$ in the control group, respectively). Serum markers of $\mathrm{I} / \mathrm{R}$ injury, such as AST and ALT, were also comparable between the two groups in the first postoperative week (Fig. 1).

The overall incidence of biliary complications was not significantly different between the two groups (Table 3). The incidence of early NAS (first presentation less than $1 \mathrm{yr}$ after LT) was $9 \%$ in patients receiving a donor liver $\geq 65$ yrs vs. $11 \%$ in the control group $(\mathrm{p}=0.68)$. The incidence of late NAS ( $\geq 1$ yr after LT) was $4 \%$ in the study group vs. $8 \%$ in the control group $(\mathrm{p}=0.48)$. Additionally, no significant differences were observed in the incidence of the other biliary complications such as AS, biliary leakage, and post-transplant cholangitis.

Next, we performed a separate analysis of potential risk factor for the development of any type of post-ischemic biliary complication including NAS, AS, or biliary leakage. Variables included in this analysis were donor age, CIT, WIT, and type of biliary anastomosis (duct-to-duct vs. Roux-en-Y hepaticojejunostomy). None of these variables appeared to be statistically significantly associated with the development of a post-ischemic biliary complication.

\section{Discussion}

The intention of this national multicenter study was to investigate outcome after LT of elderly donor liver grafts $(\geq 65 \mathrm{yr}$ ). In particular, we focused on the incidence of biliary complications in recipients of an elderly donor liver. The present study indicates that the use of donors above $65 \mathrm{yr}$ may result in biliary complication rates that are comparable to younger donors ( $<65 \mathrm{yr})$. Similarly, patient and graft survival rates after LT with elderly donor grafts are not different from their younger controls.

Several donor risk analyses of US and European transplant registries have reported that advanced age is an independent predictor for worse postoperative outcome after LT (16-21). Single-center studies, however, reported that elderly donor livers can be used for LT with favorable patient/graft survival rates (22-29). The results of the current study are consistent with these single-center reports. Nevertheless, our study is the first to assess outcome after LT with elderly donor livers in a national multicenter cohort. Moreover, our study was performed in a matched case analysis including stratification per center. Therefore, the risk that poor clinical outcomes after LT of elderly donor livers were compensated for good clinical outcomes achieved in another center may be 


\section{Westerkamp et al.}

Table 1. Recipient, donor, and surgical characteristics in patients who received a donor liver from an elderly donor ( $\geq 65 \mathrm{yr}$ ) vs. control patients without an elderly donor liver (donor age $<65 \mathrm{yr}$ )

\begin{tabular}{|c|c|c|c|}
\hline Variable & $\begin{array}{l}\text { Study group } \\
\text { Donor age } \geq 65 \text { yr }(n=68)\end{array}$ & $\begin{array}{l}\text { Control group } \\
\text { Donor age }<65 \text { yr }(n=136)\end{array}$ & $\mathrm{p}$-value \\
\hline \multicolumn{4}{|l|}{ Recipient variables } \\
\hline Median age $(y r)^{a}$ & $54(41-65)$ & $53(20-68)$ & 0.589 \\
\hline \multicolumn{4}{|l|}{ Gender } \\
\hline Male & $46(67 \%)$ & $76(56 \%)$ & \multirow[t]{2}{*}{0.106} \\
\hline Female & $22(33 \%)$ & $60(44 \%)$ & \\
\hline $\mathrm{BMI}\left(\mathrm{kg} / \mathrm{m}^{2}\right)$ & $26(23-29)$ & $25(23-28)$ & 0.456 \\
\hline \multicolumn{4}{|l|}{ Indication for transplantation } \\
\hline Post-necrotic cirrhosis & $43(63 \%)$ & $85(63 \%)$ & \multirow[t]{6}{*}{0.304} \\
\hline Primary sclerosing cholangitis & $11(16 \%)$ & $25(18 \%)$ & \\
\hline Primary biliary cirrhosis & $2(3 \%)$ & $11(8 \%)$ & \\
\hline Metabolic disease & $2(3 \%)$ & $9(6 \%)$ & \\
\hline Acute fulminant liver failure & $2(3 \%)$ & $4(3 \%)$ & \\
\hline Miscellaneous & $8(12 \%)$ & $2(2 \%)$ & \\
\hline MELD score & $19(15-27)$ & $20(14-25)$ & 0.537 \\
\hline Serum creatinine before $L T(\mu \mathrm{mol} / \mathrm{L})^{\mathrm{b}}$ & $85(67-114)$ & $78(64-105)$ & 0.325 \\
\hline Serum total bilirubin before $\mathrm{LT}(\mu \mathrm{mol} / \mathrm{L})^{\mathrm{c}}$ & $54(24-96)$ & $58(32-134)$ & 0.340 \\
\hline INR before LT & $1.3(1.1-1.6)$ & $1.4(1.2-1.6)$ & 0.885 \\
\hline \multicolumn{4}{|l|}{ Status on waiting list } \\
\hline Elective & $65(95 \%)$ & $129(95 \%)$ & \multirow[t]{2}{*}{1.000} \\
\hline High urgency & $3(5 \%)$ & $7(5 \%)$ & \\
\hline Waiting time on list (d) & $133(46-342)$ & $239(57-419)$ & 0.175 \\
\hline \multicolumn{4}{|l|}{ Donor variables } \\
\hline Donor risk index & $2.2(2.1-2.4)$ & $1.6(1.5-1.9)$ & 0.001 \\
\hline Median age $(y r)^{a}$ & $68(65-86)$ & $46(18-64)$ & 0.001 \\
\hline \multicolumn{4}{|l|}{ Gender } \\
\hline Male & $32(47 \%)$ & $71(52 \%)$ & \multirow[t]{2}{*}{0.519} \\
\hline Female & $36(53 \%)$ & $65(48 \%)$ & \\
\hline $\mathrm{BMI}\left(\mathrm{kg} / \mathrm{m}^{2}\right)$ & $25.4(24-28)$ & $24.6(22-26)$ & 0.017 \\
\hline \multicolumn{4}{|l|}{ Type of donor liver } \\
\hline $\mathrm{DBD}$ & $67(98 \%)$ & $134(98 \%)$ & \multirow[t]{2}{*}{1.000} \\
\hline DCD & $1(2 \%)$ & $2(2 \%)$ & \\
\hline \multicolumn{4}{|l|}{ Cause of donor death } \\
\hline Trauma & $34(50 \%)$ & $91(67 \%)$ & \multirow[t]{3}{*}{0.045} \\
\hline Cerebrovascular & $32(47 \%)$ & $41(30 \%)$ & \\
\hline Other & $2(3 \%)$ & $4(3 \%)$ & \\
\hline \multicolumn{4}{|l|}{ Graft size } \\
\hline Full size & $68(100 \%)$ & $136(100 \%)$ & 1.000 \\
\hline \multicolumn{4}{|l|}{ Organ preservation fluid } \\
\hline UW & $62(91 \%)$ & $114(84 \%)$ & \multirow[t]{3}{*}{0.290} \\
\hline HTK & $6(9 \%)$ & $20(14 \%)$ & \\
\hline Other & 0 & $2(2 \%)$ & \\
\hline \multicolumn{4}{|l|}{ Surgical variables } \\
\hline \multicolumn{4}{|l|}{ Venous anastomosis } \\
\hline Piggyback & $63(93 \%)$ & $131(96 \%)$ & \multirow[t]{2}{*}{0.236} \\
\hline Classic & $5(7 \%)$ & $5(4 \%)$ & \\
\hline \multicolumn{4}{|l|}{ Type bile duct anastomosis } \\
\hline Duct to duct & $58(85 \%)$ & $111(82 \%)$ & 0.733 \\
\hline Hepaticojejunostomy & $10(15 \%)$ & $23(17 \%)$ & \\
\hline Choledochoduodenostomy & 0 & $1(1 \%)$ & \\
\hline Cold ischemia time $^{d}$ (h:min) & $7: 25(6: 23-9: 38)$ & 8:09 (7:07-9:47) & 0.027 \\
\hline Warm ischemia time ${ }^{\mathrm{e}}(\mathrm{h}: \mathrm{min})$ & $0: 35(0: 25-0: 42)$ & $0: 37(0: 29-0: 48)$ & 0.097 \\
\hline Blood loss (L) & $3.6(2.2-6.0)$ & $3.5(2.1-6.7)$ & 0.828 \\
\hline
\end{tabular}

Data represent median with interquartile ranges (IQR) for continuous variables or numbers (percentages) for categorical variables.

$\mathrm{BMI}$, body mass index; MELD, model of end-stage liver disease; LT, liver transplantation; INR, international normalized ratio; DBD, donation after brain death; DCD, donation after circulatory death; UW, University of Wisconsin; HTK, histidine-tryptophane-ketoglutarate.

${ }^{a}$ Data are presented as range.

${ }^{\mathrm{b}} \mathrm{Normal}<110 \mu \mathrm{mol} / \mathrm{L}$, to convert the value for creatinine to $\mathrm{mg} / \mathrm{dL}$, divide by 88.4 .

${ }^{c}$ Normal $0-17 \mu \mathrm{mol} / \mathrm{L}$, to convert the value for bilirubin to $\mathrm{mg} / \mathrm{dL}$, divide by 17.1 .

${ }^{\mathrm{d}}$ Time from in situ flushing of the donor organ until the liver is removed from ice for implantation.

eTime from removal of liver from ice until reperfusion via portal vein, hepatic artery, or both. 
Table 2. Comparison of patient and graft survival rates in patients who received an elderly donor ( $\geq 65 \mathrm{yr}$ ) liver vs. control patients without an elderly donor liver ( $<65 \mathrm{yr}$ )

\begin{tabular}{|c|c|c|c|}
\hline Variable & $\begin{array}{l}\text { Study group } \\
\text { Donor age } \geq 65 \mathrm{yr} \\
(\mathrm{n}=68)\end{array}$ & $\begin{array}{l}\text { Control group } \\
\text { Donor age }<65 \mathrm{yr} \\
(\mathrm{n}=136)\end{array}$ & $\begin{array}{l}\mathrm{p}- \\
\text { value }\end{array}$ \\
\hline \multicolumn{4}{|c|}{ Patient survival (\%) } \\
\hline 90-d & $94(99-90)$ & $90(95-86)$ & 0.143 \\
\hline $1-y r$ & $90(95-85)$ & $85(90-80)$ & 0.526 \\
\hline $3-y r$ & 77 (87-68) & $77(84-70)$ & 0.949 \\
\hline \multicolumn{4}{|c|}{ Graft survival (\%) } \\
\hline 90-d & $93(96-89)$ & $87(89-80)$ & 0.281 \\
\hline $1-y r$ & $84(89-82)$ & $79(83-74)$ & 0.373 \\
\hline $3-y r$ & $75(85-65)$ & $74(81-67)$ & 0.791 \\
\hline
\end{tabular}

The value in the parentheses is the $95 \%$ confidence interval of the survival rate.

Table 3. Postoperative outcome parameters in patients who received a donor liver from an elderly donor ( $\geq 65 \mathrm{yr}$ ) vs. control patients without an elderly donor liver ( $<65 \mathrm{yr})$

\begin{tabular}{|c|c|c|c|}
\hline Variable & $\begin{array}{l}\text { Study group } \\
\text { Donor age } \geq 65 \\
\text { yr }(n=68)\end{array}$ & $\begin{array}{l}\text { Control group } \\
\text { Donor age }<65 \\
\text { yr }(n=136)\end{array}$ & $\begin{array}{l}\mathrm{p}- \\
\text { value }\end{array}$ \\
\hline \multicolumn{4}{|l|}{ Early graft function } \\
\hline Immediate function & $66(97 \%)$ & $132(96 \%)$ & 0.623 \\
\hline $\begin{array}{l}\text { Primary } \\
\text { non-function }\end{array}$ & $2(3 \%)$ & $6(4 \%)$ & \\
\hline \multicolumn{4}{|l|}{ Late graft function } \\
\hline $\begin{array}{l}\text { Need for } \\
\quad \text { retransplantation }\end{array}$ & $5(7 \%)$ & $12(8 \%)$ & 0.117 \\
\hline \multicolumn{4}{|l|}{ Biliary complications } \\
\hline Early NAS (<1yr) & $6(9 \%)$ & $15(11 \%)$ & 0.684 \\
\hline $\begin{array}{l}\text { Late NAS } \\
\qquad(\geq 1 \mathrm{yr})\end{array}$ & $3(4 \%)$ & $11(8 \%)$ & 0.475 \\
\hline Anastomotic stricture & $11(16 \%)$ & $25(18 \%)$ & 0.697 \\
\hline Biliary leakage & $8(12 \%)$ & $9(7 \%)$ & 0.361 \\
\hline $\begin{array}{c}\text { Postoperative } \\
\text { cholangitis }\end{array}$ & $14(21 \%)$ & $20(14 \%)$ & 0.452 \\
\hline \multicolumn{4}{|l|}{ Other complications } \\
\hline $\begin{array}{l}\text { Hepatic artery } \\
\text { thrombosis }\end{array}$ & $1(2 \%)$ & $3(2 \%)$ & 0.658 \\
\hline $\begin{array}{l}\mathrm{HCV} \text { recurrence in } \\
\text { patients with } \\
\text { primary HCV }\end{array}$ & $\begin{array}{l}\text { 2/4 patients } \\
(50 \%)\end{array}$ & $\begin{array}{l}\text { 7/14 patients } \\
(50 \%)\end{array}$ & 1.000 \\
\hline Median ICU stay (d) & $3(2-7)$ & $2(1-5)$ & 0.931 \\
\hline
\end{tabular}

Data represent median with interquartile ranges (IQR) for continuous variables or numbers (percentages) for categorical variables.

NAS, non-anastomotic stricture; HCV, hepatitis C virus infection; ICU, intensive care unit.

minimized. Furthermore, in our study, several confounding factors were excluded due to the fact that recipients of an elderly donor liver and their control recipients were matched for MELD score, type of donation (DBD/DCD), and recipient age. Next to single-center reports with good postoperative outcome after LT with elderly donor livers (2229), the incidence of other major donor-related risk factors such as DCD and split liver donation is minimal in the current series. Likewise, it should be noticed that these elderly donor liver grafts were transplanted in relatively stable patients without high MELD scores and without major risk factors for postoperative graft failure (e.g. presence of HCV cirrhosis).

A plausible explanation for excellent postoperative outcomes after LT of elderly donor livers could be the short CIT obtained in the current series. The median CIT was 7:25 (h:min) in the group recipients of an elderly donor liver graft. In the Netherlands, donor livers are nationally allocated and due to short travel distances and parallel surgical procedures, we are able to keep the CIT short (preferably less than $8 \mathrm{~h}$ ). In general, there may be a threshold at which injury caused by ischemia and I/R injury becomes irreversible and influences substantially postoperative outcome. With respect to elderly donor livers, it is known that older-aged livers are more prone to ischemia and $\mathrm{I} / \mathrm{R}$ injury (5-7). When elderly donor livers are used for LT, it is therefore necessary to keep the CIT as short as possible to withstand the harmful effects of ischemia and $I / R$ injury. In our study, recipients of an elderly donor liver showed postoperative serum levels of the ischemic injury markers, AST and ALT, similar to those of their younger controls. Ischemia/ reperfusion injury-related graft failure is mainly manifest within the first $90 \mathrm{~d}$ postoperative (7, 16). In our series, no differences in 90-d graft survival rates were observed between the group recipients of an elderly donor liver and the recipients of a younger donor liver graft.

In our study, we did not find an association between advanced donor age and biliary complications such as NAS, AS, biliary leakage, and posttransplant cholangitis. However, in other retrospective studies, a positive relationship between elderly donor livers and NAS has been reported $(13,30,31)$. Recently, three independent clinical studies have demonstrated that major epithelial cell loss in the extrahepatic bile ducts can be seen in more than $80 \%$ of the donor livers (DBD and DCD) after cold storage (32-34). The observation that only the minority develops NAS has led to the hypothesis that proliferation and regeneration of the bile duct wall, rather than ischemic injury alone, are important factors in the pathogenesis of NAS (35). Because of the poorer regeneration capacity due to the aging process (2-4), we can assume that elderly donor livers are more susceptible for the development of NAS. Nevertheless, in the current study, the incidence of the ischemiarelated type of NAS (NAS presentation within 

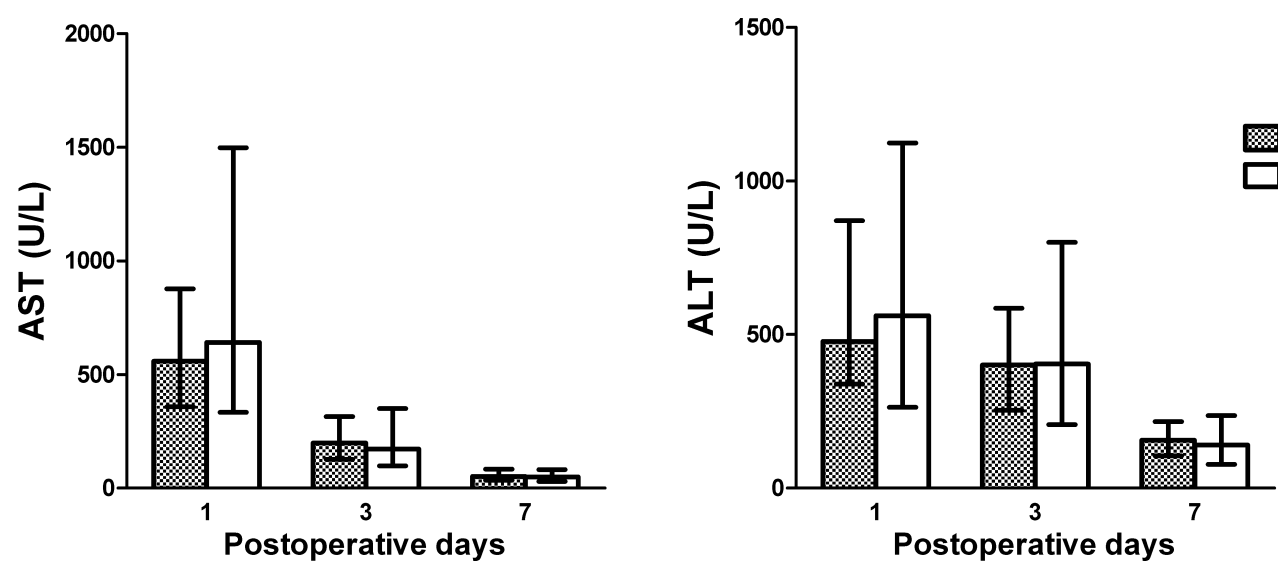

Fig. 1. Postoperative serum markers of ischemia/reperfusion injury at day 1,3 , and 7 postoperative. There were no significant differences between serum levels of aspartate aminotransferase (AST) and alanine aminotransferase (ALT) in recipients with an elderly donor liver $(\geq 65 \mathrm{yr})$ and recipients of a younger graft $(<65 \mathrm{yr})$ at postoperative day 1, 3, and 7 . Data represent median values with IQR (error bars). AST normal value $<48 \mathrm{U} / \mathrm{L}$ and ALT normal value $<42 \mathrm{U} / \mathrm{L}$.

$1 \mathrm{yr}$ ) was not higher in recipients of an elderly donor liver compared to younger controls. Therefore, we do not consider advanced donor age as a major risk factor for the development of NAS after LT.

By the use of a national protocol for allocation and LT of elderly donor livers in the Netherlands, we are able to keep the CIT short. We believe this is currently the best strategy to deal with donor livers with advanced donor age. Other techniques to improve outcome after LT of elderly donor livers could come from more sophisticated techniques such as machine preservation. It has been shown that a short period of oxygenated machine perfusion at the end of the period of static cold storage under hypothermic conditions $\left(10^{\circ} \mathrm{C}\right)$ could lower the effects of $I / R$ injury and improve functionality of the graft (36). In addition, with (sub)normothermic machine perfusion (perfusion from 20 to $37^{\circ} \mathrm{C}$ ), ex vivo assessment of liver viability prior to LT could be examined (37). Although machine perfusion is a very promising method for improvement of graft quality during preservation of ECD livers, this technique should be studied in clinical trials. We recently initiated such a trial to examine the benefitis of hypothermic machine perfusion in DCD LT.

In conclusion, this national multicenter study demonstrates that elderly donor livers can be transplanted with excellent postoperative outcomes, when a policy is adapted wherein the CIT is kept as short as possible and recipient and additional donor-related risk factors are kept to a minimum. Moreover, this study does not confirm an association between biliary complications (especially NAS) and elderly donor livers. Therefore, by the use of strict logistics and eliminating recipient and additional donor-related risk factors, elderly donors could be safely used for expanding the donor pool.

\section{Acknowledgements}

We are grateful to Cynthia Konijn (Dutch Transplantation Foundation) for her support in obtaining data of elderly donors.

\section{Funding}

In general, this work was not supported by grants or other financial resources.

\section{Authors' contributions}

Andrie C. Westerkamp: This author designed the study, conducted the study, analyzed the data, and wrote the manuscript; Kerem S. Korkmaz, Jan T. Bottema, Jan Ringers, Wojciech G. Polak, Aad P. van den Berg, Bart van Hoek, and Herold J. Metselaar: This author helped design the study, conducted the study, and wrote the manuscript; Robert J. Porte: This author designed the study, conducted the study, reviewed the analysis of the data, and approved the final version of the manuscript.

\section{References}

1. Durand F, Renz JF, Alkofer B et al. Report of the Paris consensus meeting on expanded criteria donors in liver transplantation. Liver Transpl 2008: 14: 1694.

2. TAUB R. Liver regeneration: from myth to mechanism. Nat Rev Mol Cell Biol 2004: 5: 836.

3. Tanemura A, Mizuno S, Wada H, Yamada T, Nobori T, IsAJI $\mathrm{S}$. Donor age affects liver regeneration during early 
period in the graft liver and late period in the remnant liver after living donor liver transplantation. World J Surg 2012: 36: 1102.

4. Jimenez-Romero C, Caso Maestro O, Cambra Molero $\mathrm{F}$ et al. Using old liver grafts for liver transplantation: where are the limits? World J Gastroenterol 2014: 20: 10691 .

5. Deschenes M, Forbes $\mathrm{C}$, Tchervenkov $\mathbf{J}$ et al. Use of older donor livers is associated with more extensive ischemic damage on intraoperative biopsies during liver transplantation. Liver Transpl Surg 1999: 5: 357.

6. Verran DJ, Gurkan A, Dilworth P et al. Inferior liver allograft survival from cadaveric donors $>50$ years of age? Clin Transplant 2001: 15: 106.

7. Reese PP, Sonawane SB, Thomasson A, Yeh H, MarkMANN JF. Donor age and cold ischemia interact to produce inferior 90-day liver allograft survival. Transplantation 2008: 85: 1737.

8. Mateo R, Cho Y, Singh G et al. Risk factors for graft survival after liver transplantation from donation after cardiac death donors: an analysis of OPTN/UNOS data. Am J Transplant 2006: 6: 791 .

9. Spitzer Al, Lao OB, Dick AA et al. The biopsied donor liver: incorporating macrosteatosis into high-risk donor assessment. Liver Transpl 2010: 16: 874.

10. Maluf DG, Edwards EB, Stravitz RT, Kauffman HM. Impact of the donor risk index on the outcome of hepatitis $\mathrm{C}$ virus-positive liver transplant recipients. Liver Transpl 2009: 15: 592.

11. Rahmel A. Annual Report 2013; Leiden;2013. Eurotransplant Foundation. ISBN-EAN: 978-90-71658-32-7.

12. Op den Dries S, Sutton ME, Lisman T, Porte RJ. Protection of bile ducts in liver transplantation: looking beyond ischemia. Transplantation 2011: 92: 373 .

13. Heidenhain C, Pratschke J, Puhl G et al. Incidence of and risk factors for ischemic-type biliary lesions following orthotopic liver transplantation. Transpl Int 2010: 23: 14 .

14. Dubbeld J, Hoekstra H, Farid W et al. Similar liver transplantation survival with selected cardiac death donors and brain death donors. Br J Surg 2010: 97: 744.

15. Westerkamp AC, de Boer mt, van den Berg AP, Gouw AS, Porte RJ. Similar outcome after transplantation of moderate macrovesicular steatotic and nonsteatotic livers when the cold ischemia time is kept very short. Transpl Int 2015: 28: 319.

16. Feng S, Goodrich NP, Bragg-Gresham JL et al. Characteristics associated with liver graft failure: the concept of a donor risk index. Am J Transplant 2006: 6: 783.

17. Braat AE, Blok JJ, Putter H et al. The Eurotransplant donor risk index in liver transplantation: ET-DRI. Am J Transplant 2012: 12: 2789.

18. Adam R, Cailliez V, Majno P et al. Normalised intrinsic mortality risk in liver transplantation: European Liver Transplant Registry study. Lancet 2000: 356: 621.

19. Cuende N, Miranda B, Canon JF, Garrido G, MateSANZ R. Donor characteristics associated with liver graft survival. Transplantation 2005: 79: 1445.

20. Halldorson JB, Bakthavatsalam R, Fix O, Reyes JD, Perkins JD. D-MELD, a simple predictor of post liver transplant mortality for optimization of donor/recipient matching. Am J Transplant 2009: 9: 318.
21. Fruhauf NR, Fischer-Frohlich CL, Kutschmann M, Schmidtmann I, Kirste G. Joint impact of donor and recipient parameters on the outcome of liver transplantation in Germany. Transplantation 2011: 92: 1378.

22. Emre S, Schwartz ME, Altaca G et al. Safe use of hepatic allografts from donors older than 70 years. Transplantation 1996: 62: 62.

23. Neipp M, Bektas H, Lueck R et al. Liver transplantation using organs from donors older than 60 years. Transpl Int 2004: 17: 416

24. Cescon M, Grazi GL, Cucchetti A et al. Improving the outcome of liver transplantation with very old donors with updated selection and management criteria. Liver Transpl 2008: 14: 672.

25. KIm DY, Moon J, IsLAND ER et al. Liver transplantation using elderly donors: a risk factor analysis. Clin Transplant 2011: 25: 270.

26. Ravaioli M, Grazi GL, Cescon M et al. Liver transplantations with donors aged 60 years and above: the low liver damage strategy. Transpl Int 2009: 22: 423.

27. Martins PN, Chang S, Mahadevapa B, Martins AB, Sheiner P. Liver grafts from selected older donors do not have significantly more ischaemia reperfusion injury. HPB (Oxford) 2011: 13: 212.

28. Jimenez-Romero C, Clemares-Lama M, Manrique-Municio A, Garcia-Sesma A, Calvo-Pulido J, Moreno-GonzALEZ E. Long-term results using old liver grafts for transplantation: sexagenerian versus liver donors older than 70 years. World J Surg 2013: 37: 2211.

29. Wilson GC, Quillin RC 3rd, Wima K et al. Is liver transplantation safe and effective in elderly $(>/=70$ years $)$ recipients? A case-controlled analysis. HPB (Oxford) 2014: 16: 1088.

30. Faber W, Seehofer D, Puhl G et al. Donor age does not influence 12-month outcome after orthotopic liver transplantation. Transplant Proc 2011: 43: 3789.

31. Serrano Mt, Garcia-Gil A, Arenas J et al. Outcome of liver transplantation using donors older than 60 years of age. Clin Transplant 2010: 24: 543.

32. Hansen T, Hollemann D, Pitton MB et al. Histological examination and evaluation of donor bile ducts received during orthotopic liver transplantation-a morphological clue to ischemic-type biliary lesion? Virchows Arch 2012: 461: 41.

33. Brunner SM, Junger H, Ruemmele $P$ et al. Bile duct damage after cold storage of deceased donor livers predicts biliary complications after liver transplantation. J Hepatol 2013: 58: 1133.

34. Op den Dries $\mathrm{S}$, Westerkamp AC, Karimian $\mathrm{N}$ et al. Injury to peribiliary glands and vascular plexus before liver transplantation predicts formation of non-anastomotic biliary strictures. J Hepatol 2014: 60: 1172.

35. Karimian N, Op den Dries S, Porte RJ. The origin of biliary strictures after liver transplantation: is it the amount of epithelial injury or insufficient regeneration that counts? J Hepatol 2013: 58: 1065.

36. Dutkowski P, Schlegel A, de Oliveira M, Mullhaupt B, Neff F, Clavien PA. HOPE for human liver grafts obtained from donors after cardiac death. J Hepatol 2014: 60: 765 .

37. Dutkowski P, Linecker M, DeOliveira ML, Mullhaupt B, Clavien PA. Challenges to liver transplantation and strategies to improve outcomes. Gastroenterology 2015: 148: 307. 